This is an author produced version of a paper published in The British Journal of Dermatology. This paper has been peer-reviewed but does not include the final publisher proof-corrections or journal pagination.

Citation for the published paper:

Wallengren, J and Dahlback, K

"Familial brachioradial pruritus."

Br J Dermatol. 2005 Nov;153(5):1016-8

http://dx.doi.org/10.1111/j.1365-2133.2005.06795.x

Access to the published version may require journal subscription.

Published with permission from: Blackwell Synergy 


\title{
Familial brachioradial pruritus
}

\author{
Joanna Wallengren, ${ }^{*} \mathrm{MD}, \mathrm{PhD}$ and Karin Dahlbäck, ${ }^{+} \mathrm{MD}, \mathrm{PhD}$
}

Department of Dermatology, University Hospital, Lund, * and Lakarhuset Ellenbogen, Malmö, , Sweden

\author{
Corresponding author \\ Joanna Wallengren, \\ Department of Dermatology \\ University Hospital \\ SE-221 85 Lund \\ Sweden \\ Tel: +46 46173152 \\ Fax: +46 46173947 \\ e-mail: Joanna.Wallengren@derm.lu.se
}




\section{Summary}

Background The cause of brachioradial pruritus (a localized itching on the arms or shoulders) is controversial. A hereditary form of this condition has not been reported.

Objectives To describe occurrence of brachioradial pruritus in several members of one family.

Patients and methods The pedigree of the three generations and the history of brachioradial pruritus was outlined. Four sisters were investigated by radiography of the cervical spine. Results Five sisters and one brother, together with five daughters of theirs suffered from recurring brachioradial pruritus. The sisters had had occupations requiring heavy lifting, spent much time outdoors and exposed themselves extensively to the sun. Several complained of neck pain and cervical radiographs of four of them indicated arthrosis.

Conclusions Spinal disease alone cannot explain the symptoms of brachioradial pruritus, which in our patients was characterized by symptom-free periods broken off by relapse late in the summer each year. The pedigree suggests this hereditary form of brachioradial pruritus to be dominant and possibly x-linked.

\section{Keywords}

Brachioradial pruritus, cervical arthrosis, familial, itch, sun 


\section{Introduction}

Brachioradial pruritus was first reporteded by Waisman 1968, who termed it solar pruritus of the elbows, describing its occurrence in patients in Florida who showed a localized itch of the skin on the dorso-lateral aspect of the arm (1). A group of 110 Hawaian patients with chronic intermittent pruritus have since been described in two reports $(2,3)$.

In one of these, Walcyk and Elpern suggested that brachioradial pruritus is a photoneurological disorder caused by sun-induced damage to nerve endings that results in pruritus and altered sensation in susceptible individuals (2). On the other hand, Hail in South Africa, suggested that brachioradial pruritus may be caused by nerve injury to the cervical spine or by nerve compression at other locations because 5 out of his 14 patients had a history of neck trauma or arthritis (4). In considering 76 brachioradial pruritus patients reported in the literature and examining 22 additional patients, Goodkin et al found 30 of these patients to have cervical spine disease (5).

The present study concerns brachioradial pruritus in five sisters and one brother stemming from a family of twelve children, as well as in five daughters of theirs. To our knowledge, this is the first report of familial brachioradial pruritus to date.

\section{Case 1 (II:12).}

A 59-year-old woman was referred for the evaluation and treatment of severe itch on the radial aspect of her lower arms. For the past 12 years her itch had been recurrent, appearing in August and lasting until December, reappearing at the end of the summers that followed. Being born and living at the seaside, she had sunbathed frequently ever since early childhood and engaged in many outdoor activities as an adult. She worked as a clerk and reported problems of neck pain. Examination, which occurred in November, showed her to have 
normal appearing skin with hypoestehesia to pinprick. A cervical radiograph showed there to be arthrosis of the uncovertebral joint C5.

The patient reported that she was one of 12 siblings, six sisters and six brothers, and that four of her sisters (II: 3, II: 4, II: 5 and II: 7) and one of her brothers (II:8) had similar symptoms of itch or a burning sensation appearing at the end of each summer from the age of about 45 years onwards. One sister (II: 10) and one of the brothers (II: 2) were dead. The pedigree is shown in figure 1.

All sisters examined had normal looking skin on the shoulders and arms, Fitzpatrick type II or I and reported a frequent exposure to the sun since childhood.

\section{Case 2 (II:3).}

The oldest of the sisters, 73 years of age, had a 28-year history of recurrent itch on the lateral aspect of her upper arms. Her job in a school kitchen required her to lift many heavy objects and she suffered from neck pain. An X-ray of the cervical spine revealed arthrosis of the intervertebral joint C7 and severe arthrosis of the uncovertebral joints C5-C6, with narrowing of the foramina. Her two daughters, 53 (III:3) and 52 years (III:4) of age, had also suffered from recurrent itch since the age of $45-50$.

\section{Case 3 (II:4).}

71 years old woman had a 26-year history of recurrent itch on the lateral aspect of her upper arms. She had worked as a shopkeeper and suffered from neck pain. An X-ray of the cervical spine revealed arthrosis of the uncovertebral joints C5-C6 and a reduction in the height of disc C6. Her two daughters (III:5 and III:6), also had recurrent itch since 18 and 20 years of age, respectively. 


\section{Case 4 (II:7).}

67 years old woman had a 13-year history of recurrent itch on the radial aspect of her lower arms and sometimes on her shoulders. She had worked as a nurse and suffered from neck pain. An X-ray of the cervical spine revealed severe arthrosis of the uncovertebral joints C5C6, with narrowing of the foramina, a prominent reduction in the height of discs C5-C6, a severe arthrosis of intervertebral joint C7 and compression of vertebra C5. Her only daughter (III:12) had had recurrent itch since the age of 37-38, but that none of her four sons (III:11, III:13, III:14 and III:15) had any problems of this sort.

\section{Case 5 (II:5).}

This fifth, 69-year-old sister, living elsewhere in Sweden, had suffered of itch affecting her upper and lower arms for about 20 years. She had worked for many years at a restaurant and later as a clerk. No clinical examination or cervical radiograph was performed. Her only son (III:7) had no problems of itch.

\section{Other family members.}

The status of the two members of generation I is unknown. Both in generations II and III, all the women, except one sister who was no longer alive (II:10) and two daughters (III-18 and III-19), 25 and 38 years old resp, were afflicted. For generation II, the status of all brothers (II:I, II:2, II:6, II:8, II:11) was unknown, although one (II:8) had mentioned suffering from itch. The following sons in generation III were known to not be afflicted: III:7, III:11, III:13, III: 14, III:15, III:16, III: 17 and III:20. No information regarding the status of the following sons and daughters in that generation was available: III: 1, III: 2. III: 8, III: 9, III: 10. The findings are summarized in table 1. 


\section{Discussion}

Our patients in the second generation of 59-73 year old sisters, all having had occupations involving heavy lifting, reported neck pains. Cervical radiography of two of our patients (II:3 and II:7) displayed a narrowing of foramina between the fifth and sixth cervical vertebral bodies, which could result in a nerve root impingement. Narrowing of foramina is most common at this level of the cervical column, being demonstrated in 22\% of 160 asymptomatic individuals between thirty and seventy years of age (6). Radiography of the cervical spine is a crude method, correlating poorly with clinical dysfunction or pain. With aging, degenerative changes increase in the cervical column, occurring in about $75 \%$ of asymptomatic individuals at age of 60-70 years (6). The only definitive diagnostic means of determining nerve root impingement currently available is MRI, which has been performed on only five of the published cases of brachioradial pruritus, one of whom had a spinal cord tumor which led to brachioradial pruritus involving the C5-C6 dermatomes $(7,8)$. Cervical spine disease is normally a permanent disorder, and one would expect continuous neuropathic pain or itch as a consequence of it. Spinal disease alone cannot explain the symptoms of brachioradial pruritus, which in our patients was characterized by symptom-free periods broken off by relapse late in the summer each year.

All the sisters and their daughters who presented symptoms had habits of frequent exposure to the sun. This accords with the fact that most cases assumed to be year-round have been reported from tropical or subtropical zones, whereas patients from temperate zones have been found to show seasonal occurrence (9-15).

As is apparent from the pedigree, recessive inheritance can be excluded. The distribution of affected individuals is clearly compatible with autosomal dominant transmission with a preferential expression in women, although X-linked dominant inheritance remains a possibility. No familial form of brachioradial pruritus has so far been described, but there is a 
report of another localized neuropathic pruritus, notalgia paresthetica, being inherited in a similar way (16).

\section{Acknowledgement}

The study was supported by the Welander and Finsen Foundation. We are grateful to Dr Felix Mitelman for the discussion we have had on the inheritance within this family and Dr Robert Goldsmith for the revision of the text.

\section{References}

1.Waisman M. Solar pruritus of the elbows (Brachioradial summer pruritus). Arch Dermatol 1968; 98: 481-485.

2. Walcyk PJ; Elpern DJ. Brachioradial pruritus: a tropical dermopathy. Br J Dermatol 1986; 115: $177-180$.

3. Knight TE, Hayashi T. Solar (brachioradial) pruritus-response to capsaicin cream. Int $J$ Dermatol 1994; 33: 206-209.

4. Heyl T. Brachioradial pruritus. Arch Dermatol. 1983; 119: 115-116.

5. Goodkin R, Wingard E, Bernhard JD. Brachioradial pruritus: cervical spine disease and neurogenic/neuropathic pruritus. J Am Acad Dermatol 2003; 48: 521- 524.

6. Friedenberg ZB, Miller WT. Degenerative disc disease of the cervical spine. A comparative study of asymptomatic and symptomatic patients. J Bone Joint Surg Am. 1963; 45: 11711178.

7. Fisher DA. Brachioradial pruritus wanted: a sure cause (and cure) for brachioradial pruritus. Int J Dermatol 1997, 36: 817-818.

8. Kavak A, Dosoglu M. Can a spinal cord tumor cause brachioradial pruritus. J Am Acad Dermatol 2002; 46: 437-440. 
9. Goodless DR, Eaglstein WH. Brachioradial pruritus: treatment with topical capsaicin. J Am Acad Dermatol 1993; 29: 783- 784.

10. Stellon A. Neurogenic pruritus. An unrecognised problem? A retrospective case series of treatment by acupuncture. Acupunct Med 2002; 20: 186-190.

11. Kestenbaum TY, Kalivas J. Solar pruritus. Arch Dermatol 1979; 115: 1368.

12. Bech-Thomsen N, Thomsen K. Solar pruritus. Acta Derm Venereol 1995; 75: 488-489.

13. Wallengren J. Brachioradial pruritus: a reccurrent solar dermopathy. J Am Acad Dermatol 1998; 39: 803- 806.

14. Veien NK, Hattel T, Laurberg G, Spaun E. Brachioradial pruritus. J Am Acad Dermatol 2001; 44: 704- 705.

15. Wallengren J, Sundler F. Cutaneous field stimulation (CFS) in treatment of severe localized itch. Arch Dermatol. 2001; 137: 1323-1325.

16. Comings DE, Comings SN. Hereditary localized pruritus. Arch Dermatol 1965; 92: 236237. 
Table 1. Summary of case histories of eleven related individuals affected by recurrent seasonal brachioradial pruritus.

$\begin{array}{llccccc}\text { Nr } & \text { Sex } & \begin{array}{c}\text { Extensive } \\ \text { exposure to sun }\end{array} & \begin{array}{c}\text { Season when } \\ \text { affected }\end{array} & \begin{array}{c}\text { Age when } \\ \text { symptoms started }\end{array} & \text { Neck pain } & \begin{array}{c}\text { Cervical } \\ \text { arthrosis }\end{array} \\ \text { II: } 12 & \text { female } & + & \text { autumn } & 45 & + & + \\ \text { II: } 3 & \text { female } & + & \text { autumn } & 45 & + & + \\ \text { II: } 4 & \text { female } & + & \text { autumn } & 45 & + & + \\ \text { II: } 7 & \text { female } & + & \text { autumn } & 54 & + & ? \\ \text { II: } 5 & \text { female } & + & \text { autumn } & 49 & ? & ? \\ \text { II: } 8 & \text { male } & + & \text { autumn } & \text { ? } & \text { ? } & \text { ? } \\ \text { III: } 3 & \text { female } & + & \text { autumn } & 45 & \text { ? } \\ \text { III: } 4 & \text { female } & + & \text { autumn } & 45 & ? \\ \text { III: } 5 & \text { female } & + & \text { autumn } & 18 & ? \\ \text { III: } 6 & \text { female } & + & \text { autumn } & 20 & ? \\ \text { III: } 12 \text { female } & + & \text { autumn } & 37 & ?\end{array}$


Legends.

Fig 1. Brachioradial pruritus (black) in a family: pedigree of three generations.

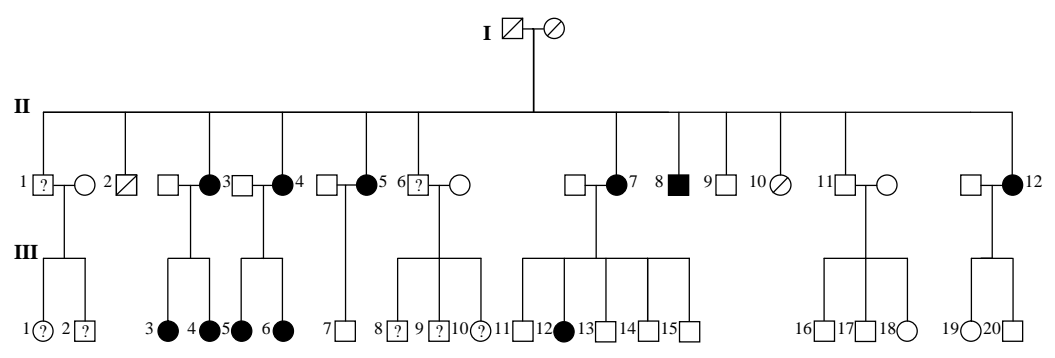

